\title{
What's in it for me? The utility of psychiatric treatments from the perspective of the person in recovery
}

\author{
LARRY DAVIDSON, REBECCA MILLER, ELIZABETH FLANAGAN
}

\begin{abstract}
The aim of this contribution is to explore how different treatments are experienced from the perspective of individuals with mental illnesses. We used data drawn from qualitative, narrative interviews. When asked to discuss their lives, people rarely discuss their psychiatric treatment. When asked about treatment, they describe hospitalization and medication but not outpatient care. What is described as most helpful are relationships with others, especially in 24-hour centers, clubhouses, and userrun organizations; places where they report feeling that they are accepted, understood, and cared about. Also important are experiences of "giving back" to others and employment as ways of increasing participants' sense of self-worth and value. Participants also indicated the importance of medication, but described protracted processes of having to find the right prescriber, the right medication, at the right dosage, and taking the medication long enough to derive its benefits. For others, symptoms were described as being an integral part of who they were and not something they wanted to eliminate. Traditional treatments (e.g., medication), if given by a practitioner who understands the person and is willing to try to find the right medication and dosage, may serve as a foundation for instrumental experiences of being accepted, understood, valued, and being able to give back to others.
\end{abstract}

We have conducted, listened to, and analyzed hundreds of interviews of individuals living with serious mental illnesses. What has perhaps been the single most surprising thing about these interviews is how little the individuals involved talked about treatment. Had we not been invited to write an essay on this topic, in fact, it is unlikely that we would have chosen to do so, so seldom is this topic broached in the stories people tell about their lives. It is not that they are reluctant to do so, as one might at first imagine, due to stigma, embarrassment, or some lingering sense of the sanctity of the confidentiality of their care, like some tight-lipped psychotherapists. It is just that it does not seem to occur to them to talk about it unless they are specifically asked to do so. When asked, they are forthcoming and their perspectives on and experiences of treatment differ widely depending on the circumstances, the treatments they received, the circumstances under which these treatments were offered, the treatments' effects and side effects, and, in particular, the treater as a person.

Address for correspondence: Dr. L. Davidson, Program for Recovery and Community Health, Department of Psychiatry, Yale University School of Medicine, Erector Square, Building 1, 319 Peck Street, New Haven, CT 06513 (USA).

Fax: (203) 764-7595

E-mail: Larry.Davidson@Yale.edu

Declaration of Interest: The authors have no conflicts of interest to declare.
For the purpose of this essay, we will describe some of these various responses regarding treatment drawn from our body of narrative research and from that of a few colleagues. Following the technique of a good narrative interviewer, we will take our lead from the participants in our studies as to what is most important, telling their stories in as much the same ways, and using much the same words, as they did.

In this regard, what individuals with mental illnesses most often talk about as having been most helpful to them are not specific treatments - such as psycho-education, skill building, or psychotherapy - but rather specific people. While we learned this fact early in terms of people's lives beyond the boundaries of the mental health system (e.g., friends, family), this point was driven home to us in terms of life inside the mental health system as well when one of our students chose to focus in her doctoral dissertation on patients' experiences of outpatient treatment. She carefully framed her opening question to elicit stories of outpatient care but then became very frustrated in the pilot phase of the study when after the first four interviews not one person had talked about their experiences of treatment per se. To a person, they all understood the term "treatment" to apply only to what transpired in the hospital. Nothing that occurred outside of the hospital setting was considered by them to be treatment, with the sole exception of medications. After additional trial and error, it eventually became clear that the most effective way to frame questions in order to elicit the kind of stories the student was seeking was to ask par- 
ticipants about their relationships with outpatient service providers. Once provided with this entrée of the relationship, people were readily able to describe various aspects of and experiences in the land of outpatient mental health care. In apparent confirmation of the research which has shown that the most effective element of psychotherapy is the relationship with the practitioner, participants had little to say about specific interventions or approaches outside of relationships with specific people. This focus on relationships continued through stories of experiences at psychosocial clubs, 24-hour or drop-in centers, and user-run programs where participants derived a sense of community, where they felt they belonged, where they could 'hang out' with their peers, and which offered some people a launching pad for forays into the broader community. For many people, it was in attending these programs that they first met other people who had or were experiencing the same kinds of problems they were. This helped in numerous ways, including "validating" their own experiences and decreasing their isolation and loneliness as well as beginning to offer them ways to address their complex, unmet needs; needs which now no longer seemed as strange, alien, or unique to them. The following three accounts from three different participants capture some of these experiences and their perspectives on them:

\footnotetext{
"I started going there and met people who were in the same situation. That was the first time I ever met people who were ill, and that was a very positive experience for me. Because you were accepted and seen in a way. I liked that a lot. You don't have to say much, but the closeness and fellowship is common ... I think I meant something to them and they sort of cared about me, and it isn't like that at home, so it was very positive that you were seen and accepted in a way. I experienced that as really unique. That meant a lot to me".

"I guess the service user organization was really the turning point ... we're all sitting in the same boat, we understand one another, we accept one another - we should be able to be the persons we are - even if I don't feel good some days, no one thinks anything about it, they don't stare at me or anything like that - can be who I am. Even if I'm not feeling well I can get out-come to the club - and not just lie around at home all day ... It's all about basic needs: meeting people, going out, talking with someone, whatever - being accepted just as you are". "We started to talk to each other about our sickness, we talk about the pills we took, compared, 'What are you on, how many milligrams, do you feel tired in the mornings or not?' And most of them smoke too - you go out, take a
}

cigarette break - talk about the weather or how bad you feel. That's how you get to know one another. I went there everyday although I was psychotic ... They're friendly, they're friendly and they're kind, they can joke with you, and above all they understand. If I have a problem or something that worries me, they listen and talk about it and their way of being to me is friendly. They treat me with respect and understanding. So I feel understood, that there is someone who listens, I feel validated and it helps me, my problems are not so big anymore when I talk with them. I feel that I'm heard, I'm understood, validated. I feel that I get respect".

In this case as well participants did not talk specifically about the more programmatic elements of these centers such as psycho-educational or rehabilitative activities; i.e., those activities which might be 'reimbursable'. Instead, they focused on the relationships developed with their peers and, at times, with the staff (who, in user organizations, are also their peers) and the feelings of being accepted, understood, and cared about by them. While within psychiatry there has been a movement away from a more explicit focus on relationships toward the type or content of treatment - including an assumption that such feelings have nothing to do with mental illness per se in the lives of our participants these issues were seen as crucial, and as providing a necessary foundation for any further efforts toward recovery. As one woman, whom we call "Fanny," emphasizes below, not being "confirmed" contributed to her illness and left her in a state others have described as being "a nobody no where" (Davidson, 2003); a position Deegan describes as one in which there is no one left to do battle with the illness (Deegan, 1993).

"I talk about the problems I have, for example that I'm having a hard time finding a job. So they reply that it's really hard to find a job these days, many people are unemployed-they confirm what I say, they confirm my words with their own. And they tell me: 'Don't give up, keep trying, you look nice and you're outgoing and you're creative and you'll surely find some job somewhere.' And like when I got a job at a large department store, just as an extra, they said: 'Congratulations Fanny!' and hugged me and congratulated me, saying: 'How well things are going for you.' ... I need to feel confirmed. I need to be seen ... I feel ill when I'm not confirmed ... When I'm confirmed ... I feel that my value is confirmed, that I am worth something, that I'm part of a group. I belong to something. Like I'm not nothing, I'm someone".

Epidemiologia e Psichiatria Sociale, 17, 3, 2008 
These relationships appear to be different from those participants are able to develop in more traditional "clinic" settings, as suggested by one Swedish participant, who said:

\begin{abstract}
"On Thursdays they have something going on in the evening; a barbeque, play music and just about everything. It costs only 10 krona and is very cheap. So yes, this place has helped me. It's better than going to the 'psych clinic.' They have this lounge suite [at the psych clinic]. Everyone sits on the couch and stares at each other, from 8 in the morning to 12. That really feels like doing hard time. I only go up there to get my medication. Down here it's a different environment altogether. It's like a little café. We can sit outside in the summer... and everyone is so nice. At the clinic, you feel that they're more like staff. Here, they're more like friends".
\end{abstract}

American participants have been perhaps even more critical in distinguishing between the kinds of relationships allowed in clinical settings from those cultivated in user-oriented programs. In clinical settings, relationships are described as hierarchical and asymmetrical, as relationships in which they are expected to disclose intimate details of their personal lives and receive advice and care from others while not being offered any information about the lives of staff and not being allowed to offer anything in return. This may result at times in participants feeling diminished, inferior, and less than human. While they may still experience being cared for, the experience appears to be that of being cared for as a 'mental patient' rather than as a fellow human being.

In contrast, in other passages participants talk about the importance of being able to "give back" to their peers and staff at user-oriented programs and increases in their sense of self-worth and value that derive from seeing that they have things to offer that are valued by others. This is conveyed in the following three passages.

\footnotetext{
"If I'm sitting at home and feeling miserable, it's like I'm the only person in the whole world whose life is like this - then I'm just a piece of shit. If I come here and see that there are others who have the same kind of life as mewell, we can help each other, give and take. That's how human relationships work".

"By helping others you're not totally worthless. Like it's a natural, human characteristic that if you're able to help others than you're worth something ...It's essential to life for people to feel necessary... Giving something to someone else makes you feel worth something yourself".
}

\begin{abstract}
"It made me feel like I was being helpful and in situations like that I don't think so much about my illness. It kind of goes on the back burner because sometimes I just think about my illness and it seems like when I'm helping somebody or somebody says something nice to me ... as soon as people say that, oh, you look good, things like that, it makes me feel better about myself".
\end{abstract}

As suggested in this last passage, in addition to deriving a sense of value and self-worth through giving to others, relationships that are characterized by respect and reciprocity can offer people a unique window back onto themselves; it is through the eyes (and feedback) of trusted others that they are first able to appreciate and gauge their own achievements and progress. The crucial need for and benefits derived from these kinds of relationships led one participant to suggest that using the phone and internet as ways of connecting to others is a form of rehabilitation which should be financially supported by the government:

"I call him up and he calls me up and we talk about bowling, or politics. It doesn't matter what we talk about, as long as we talk ... the mentally ill need to use the phone more, or surf [the internet] as a form of rehabilitation ...They give money to other handicapped people, those who are physically handicapped for their special equipment. But there's money available for that only because that kind of handicap is accepted. But money for our special equipment - there is none, because they're not defined [as rehabilitative]. We have to take it from our own resources...The social insurance office doesn't see it as a form of rehabilitation".

In addition to the support, acceptance, and sense of identity and belonging offered by these programs and the relationships which develop from them, participants described the importance of having places to go from and return to in their efforts to integrate into community life. In earlier publications (e.g., Davidson et al., 2001) we have described the integration process primarily in terms of interpersonal relationships. For the purposes of this essay, a better example is provided by the risks and rewards involved in returning to paid employment or, for some participants, entering the labor force for the first time. Fanny describes above two of the roles user-oriented programs play in assisting people to obtain employment, encouraging them to try and then celebrating their successes. Other roles can be providing material and instrumental support including transportation, coaching participants and enabling them to get practice

Epidemiologia e Psichiatria Sociale, 17, 3, 2008 
doing job interviews, and, finally, providing job coaching or support at the work site. Many of these same functions can be served on a one-to-one basis without a social club or day program through the individualized placement and support model of supported employment (e.g., Becker \& Drake, 1994; Drake et al., 1999). The person's perspective on this process has been described in more detail by Strauss \& Davidson (1996) and Krupa (2004). For our participants, one of the key issues involved in returning to work, whether through a program, through supported employment, or on their own, has had to do with going against the opinions of practitioners who told them they would never work again and deciding to take the risk to work even while symptoms persist (i.e., not waiting to "get better" first). As captured in the following two passages, it may be more effective to work as a path to recovery rather than waiting to recover first before working:

"If I wasn't working my job I'd end up in a hospital or something like that. Depressed all the time. But since I'm working, I'm full time, and I'm going, going, going. I just love it you know ... It's kept me from being in the hospital" (Deegan, 2005, p. 32).

"There's joy in work - instead of chasing after happiness all the time ... the right way to go is to have a job, to make sure that you have something worthwhile to do and afterwards when you sit down, feeling happy just comes as a side-effect".

As a final aspect of treatment, we turn to the issue of medications. Many participants talk about the importance of medications, even crediting them with saving their lives. As one person described: "What is crucial for my health is taking the Risperdal, it attacks the psychosis." It is typically not a simple matter of taking one medication and gaining relief from symptoms, however. What appears to be more typical - both in our studies and in the studies of Deegan (2005) and Jenkins et al. (2005) which focused specifically on subjective experiences of medications - was a protracted process of trial and error through which people ended up finding both the right doctor or nurse, and then eventually the right medication. The "right" prescriber was someone who listened to the person, was willing to try different things, and who viewed the medication as more than just a way to reduce symptoms. As one person in Deegan's study described:

"She wants you to be the best person you can be so she tries to get medication for that. Not something that's just going to, as I call it, zombify you out and get rid of the symptoms. She wants to get rid of the symptoms but also wants you to live" (Deegan, 2005, p. 33).

In addition to finding the right prescriber and the right medication, participants report that it takes time to be able to discern the benefits of a medication as change is often incremental and slow. As a participant in Jenkins and colleagues' study described:

\section{"I think a day doesn't go by without my getting a little bit better. That's the nice thing about Clozaril. You do improve over time, you know, if you continue to take it...And it just takes a long time” (Jenkins et al., 2005, p. 221).}

Another participant in the same study reported that for her "it took like eight years" to find a medication that worked (Jenkins et al., 2005, p. 390).

As Deegan \& Drake (2006) argue, however, the relationship between people with mental illnesses and psychiatric medications is often even more complicated than this. Other complications include finding the effects of a medication to be worse than the mental illness, choosing not to take medications because of the stigma or social rejection associated with them, rejecting medications as symbols of the illness or because the person does not think she or her is ill, and choosing not to take medications as prescribed because they do not appear to be effective. Still other people describe their symptoms as being an integral part of who they are and not something they would like to eliminate via medication, as the participant in Deegan's study who said:

"I don't really see it as mania. I see it as part of me. I just see that as an extension of me when I am full of energy. I am able to do things... This is the me that I know but then there's somebody else calling it a disease, a problem. Well, for me, this problem has got me through a lot!" (Deegan, 2005, p. 33).

\section{CONCLUSION}

These findings from first-person accounts of how treatments are experienced by individuals with mental illnesses suggest that beyond psychiatric interventions, relationships with others are crucial, including ones with treaters in which the treater listens to the person and is willing to try to find the right medication and dosage to minimize symptoms while allowing the person to pursue the kind of life he or she wishes to have. This relation-

Epidemiologia e Psichiatria Sociale, 17, 3, 2008 
ship may then serve as a foundation for the crucial experiences of being accepted, understood, valued, and being able to give back to others. Future research should focus on how these experiences, and the useful relationships through which they develop, might be promoted by practitioners and through peer support, mentoring, and opportunities for people with mental illness to give back to others.

\section{REFERENCES}

Becker D.R. \& Drake R.E. (1994). Individual placement and support: A community mental health center approach to vocational rehabilitation. Community Mental Health Journal 30, 193-206.

Davidson L. (2003). Living Outside Mental Illness: Qualitative Studies of Recovery in Schizophrenia. New York University Press: New York.

Davidson L., Stayner D.A., Nickou C., Styron T.H., Rowe M. \& Chinman M.L. (2001). "Simply to be let in": Inclusion as a basis for recovery. Psychiatric Rehabilitation Journal 24, 375-388.
Deegan P.E. (1993). Recovering our sense of value after being labeled mentally ill. Journal of Psychosocial Nursing, 31(4), 7-11.

Deegan P.E. (2005). The importance of personal medicine: A qualitative study of resilience in people with psychiatric disabilities. Scandinavian Journal of Public Health 33, Suppl 66, 29-35.

Deegan P.E. \& Drake R.E. (2006). Shared decision making and medication management in the recovery process. Psychiatric Services 57(11), 1636-1639.

Drake R.E., Becker D.R., Clark R.E. \& Mueser K.T. (1999). Research on the individual placement and support model of supported employment. Psychiatric Quarterly 70, 289-301.

Jenkins J.H. \& Carpenter-Song E. (2006). The new paradigm of recovery from schizophrenia: Cultural conundrums of improvement without cure. Culture, Medicine and Psychiatry 29, 379-413.

Jenkins J.H., Strauss M.E., Carpenter E.A., Miller D. Floersch J. \& Sajatovic. M. (2005). Subjective experience of recovery from schizophrenia-related disorders and atypical antipsychotics. International Journal of Social Psychiatry 51(3), 211-227.

Krupa T. (2004). Employment, recovery, and schizophrenia: Integrating health and disorder at work. Psychiatric Rehabilitation Journal 18(1), 8-15.

Strauss J.S. \& Davidson L. (1996). Mental disorder, work and choice. In Mental Disorder, Work Disability, and the Law (ed. R. Bonnie and J. Monahan), pp. 105-130. University of Chicago Press: Chicago. 